\title{
Cerebrospinal fluid homocysteine and hydrodynamics in chronic hydrocephalus
}

\author{
EA Schmidt*1, E Caussé2, T Voisin³ ${ }^{3}$ B Vellas ${ }^{3}$, R Salvayre², M Czosnyka ${ }^{4}$ and \\ $M$ Trémoulet $^{1}$
}

\author{
Address: ${ }^{1}$ Service de Neurochirugie, Hôpital Purpan 31000 Toulouse, France, ${ }^{2}$ Laboratoire de Biochimie, INSERM U466, Hôpital Rangueil 31000 \\ Toulouse, France, ${ }^{3}$ Médecine Interne et Gérontologie Clinique, Casselardit, Hôpital Purpan 31000 Toulouse, France and ${ }^{4}$ Department of \\ Neurosurgery, Addenbrooke's Hospital Cambridge CB2 2QQ, UK \\ Email: EA Schmidt* - Schmidt.e@chu-toulouse.fr \\ * Corresponding author
}

from 50th Annual Meeting of the Society for Research into Hydrocephalus and Spina Bifida

Cambridge, UK. 30 August - 2 September 2006

Published: 21 December 2006

Cerebrospinal Fluid Research 2006, 3(SuppI I):S54 doi:I0.II86/1743-8454-3-SI-S54

(C) 2006 Schmidt et al; licensee BioMed Central Ltd.

\section{Background}

Homocysteine seems to have a direct neurotoxic effect and could increase the vulnerability to excitotoxic and oxidative injury. Hydrocephalus, a partially reversible gait and cognitive impairment, is mainly due to an ill-circulating cerebrospinal fluid (CSF). Our hypothesis is that CSF may play a role in the clearance or secretion of Homocysteine. The aim of this study is to gauge homocysteine and other thiols in the CSF of hydrocephalic patients, and to correlate these biological parameters with hydrodynamic patterns.

\section{Methods}

43 patients (24 females, 19 males, mean age: 71,6 years) were included. All patients were suspected of chronic hydrocephalus (gait alteration, urinary incontinence and cognitive decline) and enlargement of the ventricles on brain imaging. To confirm the diagnosis, we performed in clinical routine CSF hydrodynamic tests via lumbar infusion according to Czosnyka's technique. A lumbar needle was inserted. A $2 \mathrm{ml}$ sample of CSF was withdrawn for biochemical analysis. Subsequently, we measured the CSF hydrodynamics: pressure and pulse amplitude of the CSF during baseline and plateau, and calculation of the resistance to CSF outflow. Homocysteine (Hcy), Cysteine (Cys), Cysteinyl-Glycine (Cys-Gly) and Glutathione (G-
SH) were measured in CSF by capillary electrophoresis and laser induced fluorescence detection.

\section{Results}

In the CSF of the patients, the mean \pm SD values of the various thiols were: Hcy $0.24 \pm 0.05 \mu \mathrm{mol} / \mathrm{L}$, Cys $3.84 \pm 1.26$ $\mu \mathrm{mol} / \mathrm{L}$, Cys-Gly $3.33 \pm 0.92 \mu \mathrm{mol} / \mathrm{L}$ and G-SH $0.5 \pm 0.45$ $\mu \mathrm{mol} / \mathrm{L}$.

Cys and Cys-Gly were positively correlated $(\mathrm{r}=0.51 \mathrm{p}<$ $0.01)$.

Baseline CSF pressure and resistance to CSF outflow were not correlated with the thiol levels. However, the baseline pulse amplitude of ICP significantly correlated with Hcy level $(\mathrm{r}=0.36 \mathrm{p}=0.02)$.

\section{Conclusion}

Our preliminary results suggest that in hydrocephalus, hydrodynamics is not related to the level of thiols. Our clearance hypothesis is not supported by our data. However, our results raise the interest of transsulfuration pathway of the thiol metabolism in CSF. 